\section{Nevus depigmentosus}

\section{Introduction}

Nevus Depigmentosus (nevus achromicus) is a rare congenital pigmentary disorder. It is a depigmentation problem in skin which can be easily differentiated from vitiligo. Nevus anemic us is a congenital vascular anomaly that presents clinically as a hypo pigmented macule or patch.

The pathogenesis of ND is not fully understood. It is believed to be due to a functional defect of melanocytes with morphological abnormalities of melanosomes. It is also said to be a form of cutaneous mosaicism wherein an altered clone of melanocyte have a decreased ability to synthesize melanin and transport to keratinocytes.

It can be found anywhere on the body but commonly it is seen on the trunk, neck, face, and proximal part of the extremities. Clinically, three types have been described: Localized Segmental, and Linear or Whorled. Localized variant is the most common compared to the others. It is a single well circumscribed lesion with serrated borders. Segmental variant is larger in size and shape and also referred to as "segmental de-pigmentation disorder" with a sharp midline demarcation. Linear/whorled/systematized type may be extensive and have cutaneous lesions that overlap with HOI.( hypomelanosis of Ito ) The systematized variant is very rare and may have extra cutaneous manifestations such as seizures, mental retardation, hemi hypertrophy, and yellow hair.

\section{Symptoms}

These are localized white spots on skin which may affect any area of the body, but these white spots are quite stable lesions. In the majority of patients, the lesions are not completely achromic, but are hypo-pigmented and resemble splashed paint. The individual lesions are permanent and there are no effective therapies for re-pigmenting this nevus. If there is hair in an affected area, it is usually colorless or white.

\section{Treatment}

Different therapeutic modalities have been attempted to re-pigment the lesions of nevus de-pigmentosus such as PUVA, Excimer laser, and different grafting techniques. As far as treatment is considered, mostly it does not require any as it is non-progressive and adequate counseling is sufficient to allay fears about the condition especially among parents concerned about their affected child. Optional treatment modalities include Cosmetic camouflage (especially for lesions on uncovered parts of the body), psoralen-ultraviolet-A therapy, suction blister grafting. ${ }^{1-6}$
Volume I Issue I - 2017

\author{
Hayk S Arakelyan \\ General Medicine and Clinical Research,Armenian University of \\ Integrative Medicine,Armenia \\ Correspondence: Hayk S Arakelyan, Doctor of Medical \\ Sciences, PhD, Senior Expert of Interactive Clinical \\ Pharmacology, Drug Safety, Treatment Tactics, General Medicine \\ and Clinical Research. Armenian University of Integrative \\ Medicine, Armenia, Tel (3749I)-40-94-97, \\ Email spacetech_22@yahoo.co.uk
}

Received: March 28, 2017| Published: April 04, 2017

\section{Acknowledgements}

None.

\section{Conflict of interest}

The author declares no conflict of interest.

\section{References}

1. Lee HS, Chun YS, Hann SK. Nevus depigmentosus: Clinical features and histopathologic characteristics in 67 patients. J Am Acad Dermatol. 1999;40(1):21-26.

2. Sarma N, Chakraborty S. Birthmarks of clinical significance. Sarkar R, et al. editors. Advances in Pediatric Dermatology. 1st ed. India: Jaypee Brothers Medical Publishers (P) Ltd; 2014. p. 198-199.

3. Berg M, Tarnowski W. Nevus pigmentosus. Arch Dermatol. 1974;109:920.

4. Oiso N, Kawara S, Kawada A. Acquired melanocytic naevus in naevus depigmentosus. Clin Exp Dermatol. 2009;34(7):e311-e312.

5. Anstey AV. Disorders of skin of colour. Burns T, et al. editors. Rook's Textbook of Dermatology. 8th ed. New York, USA: Wiley-Blackwell Publishers; 2010. p. 44-45.

6. J Nordlund, James. The pigmentary system: physiology and pathphysiology. USA: Blackwell Publishing Ltd; 2007. 651 p. 